\title{
1. Entrepreneurial creativity and coordination of new products
}

\section{INTRODUCTION}

The advance of computing technology and the Internet in the past decade has enabled us to consume digital media such as television, magazines and video games in the virtual world, where the temporal and locational dimensions cease to be of significance. For instance, we can read an online magazine in a secluded Pacific holiday resort, play an online video game at the airport or watch an online television programme in the small hours. We can choose a time and a place that is deemed to be convenient to us, rather than restricted by the media owners' criteria regarding availability. Such empowerment of individual decision-making has also extended to the choice of alternative story lines, such as the final episode of the UK's A Touch of Frost, in which viewers were offered two choices for the ending on itv.com. The first version, which had been broadcast in April 2010, showed the hero, Detector Inspector Jack Frost, retired and finding love with the Royal Society for the Prevention of Cruelty to Animals officer Christine Moorhead. The alternative version of the ending, as a contrast, showed Frost involved in a car accident, suffering a fatal heart attack. Moorhead was forced to turn off the life support machine under the tragic circumstances.

This book aims to look at the complexity of coordination involving the production and distribution of new-to-the-world ${ }^{1}$ digital media products, $^{2}$ with a focus on television programmes, video games and magazines that could be consumed online or via an Internet download. ${ }^{3}$ Let us begin with the concept of coordination. The purpose of coordination is to attain optimum allocation of resources that enhances efficiency; hence, coordination of economic activity is a key to profit maximization. The coordination process within digital media revolves around harmonizing decisions during the process of transforming human resources, tangible resources and intangible resources into a concept-intensive product, ${ }^{4}$ which then utilizes the wireless network or the Ethernet cable for virtual distribution to users. The industry context therefore allows us to generate insight into the complexity of coordination within increasingly important creative industries, where the role of intellectual assets is critical, but understudied. 
The launch of new-to-the-world digital media products creates new brands and represents the possible launch of new franchises within existing or new entertainment space. For example, the online downloadable game Silent Hill Book of Memories, released in 2012, was derived from Konami's Silent Hill franchise, first launched in 1999. Other than the successful release of nine games, the franchise was also associated with two psychological horror films, Silent Hill and Silent Hill Revelation, ${ }^{5}$ a comic series written by Scott Ciencin first published in 2000 and a Silent Hill novel written by Sadamu Yamashita in 2006. A good example of a television franchise is John Lloyd's concept of $Q I$ (Quite Interesting), launched in 2003, which was a new satire panel game quiz show genre within comedy. The continued development of product concepts within existing digital media products generates further franchises. For example, $Q I$ had ten series by 2012. Each episode within these series was a new-to-the-world product since the host Stephen Fry asked his panellists and guests new and different obscure questions. The format of $Q I$ was also sold to Sweden's SVT1 in 2012, in which the comedian Johan Wester was appointed the host. The internationalization of $Q I$ therefore generated further products in the Swedish context that were new. Franchises also relating to magazines could be seen in the UK online magazine Families, ${ }^{6}$ which pioneered the freemium model in 1990 and combined content on parenting for 0-12 children provided by the franchise as well as local information relating to educational, arts and entertainment activities. Finally, the 'online version' of Intelligent Life, ${ }^{7}$ a sophisticated lifestyle magazine franchise, provided information on fine food, wine, books, fashion, museums, travel, and so on, as well as photo essays and cover stories on a variety of thoughtprovoking topical issues. Its launch issue in 2007 contained 'an image of a doomed, bloodied wild boar, frantically trying to outrun a pack of Poitevin hounds' and 'the hounds goring the boar's carcass' (Burrell 2007); these images related to the photo essays 'La Chasse' concerning hunting in the forests of Auvergne, France.

Though becoming a global blockbuster is much emphasized in the creative industries, ${ }^{8}$ the majority of production does not gain status and in fact only a small number of digital media products have evolved into globally recognized brands because of cultural barriers, different legal frameworks and sometimes the relatively small size of their niche market segment. We will cover both mainstream and non-mainstream digital media products in the following chapters. For example, a niche TV programme might attract only 2 million viewers on air and therefore a finite number of advertisers. It could, however, generate further economic rents via the intellectual assets, in other words, by its licensing of the programmes to international broadcasters or TV streaming on-demand service firms such as Netflix. 
The intellectual property rights in terms of the format of the programme (if applicable) could also generate substantial income stream; finally, further revenue source could be derived from the sale of the DVD box sets and related books for individual consumption. These examples highlight the role of intellectual assets in value-creation within creative industries (Caves 2000; Scott 2000).

We focus on the aforementioned digital media because they are important sectors within creative industries, whose economic activities hinge upon the exploration and exploitation of knowledge and information (Howkins 2007). What are creative industries? The UK Government officially launched the term creative industries in 1998; its Department for Culture, Media and Sports (DCMS) defines creative industries as industries which are associated with individual creativity, skill and talent, and has provided various strategic mapping such as the initial DCMS report in 2001. ${ }^{9}$ Creative industries have been a focus for policymakers in advanced economies; for instance, the European Union chose 2009 as the European Year of Creativity and Innovation. Additionally, emerging economies such as China have also addressed the need to embrace creative industries within their recent national plans for close linkage with the implementation and advancement of new digital technology and business models. Indeed, Potts (2011) pointed out that creative industries were not simply about entertainment, but were essential components within the national innovation system. He wrote $(2011$, p.2) that creative industries 'drive, facilitate and engender the origination, adoption and retention of new ideas (the innovation process) into the socio-cultural and economic system'. For example, the previous conception of video games as purely entertainment has changed to that of national strategic interests, as the US Government's National Aeronautics and Space Administration (NASA) adopted the technology and design theory behind video games to remotely control robots that operate in space as well as on the surface of planets (Freeman 2013).

\section{COORDINATING NEW-TO-THE-WORLD DIGITAL MEDIA}

A manager from a US global game firm illustrated the challenges in coordinating new-to-the-world digital media products as: 'it's really tough because uniquely in this industry I think you've got to think of important variables, one is technology and the other one is creativity ... in this industry not only do you have all that technology risks, when the game is finished you might find out it's just not fun or the market has moved 
on.' The online television, online game and online magazine sectors within the creative industries are driven by commercial reality and represent a synergy of traditional craftsmanship and modern marketing. The combination of tradition and modernity generates unlimited possibility of unforeseen scenarios that could have posed challenges during the production and distribution processes.

Grant and Jordan (2012, p.129) pointed out: 'a limited repertoire of routines can be performed highly efficiently with near-perfect coordination'; to illustrate this point, we can look at the duplication of an online TV programme in the format of boxed DVD gift sets for the EU Christmas market. The technological capability of global firms such as Handisc, OK Media or Sony DADC mean that the coordination process is predictable and a quality standard of zero defect for gift sets is achievable. Even though the technology used in the production is relatively advanced for the initial master copy, the mass production of the gift set is highly standardized and is handled in a routine procedure. Similarly, the mass marketing of the merchandise could follow a standardized marketing campaign. This contrasts with the complexity in the creation of an online TV series, which requires efficiency in transforming creative inputs from script writing, acting, lighting, recording, and so on, to a craftsmanshipquality programme in terms of fun and entertainment, appealing to the sense of humour of a certain market segment(s).

Historically, economists explained coordination in the context where key actors undertake economic activities within the boundary of firms or in the competitive market, which constitute the primary function of the capitalist market system (Smith 1776). As preferences, resources and technical know-how vary, coordination problems could arise as discussed in game theory (for example Arrow 1962; Casson 1982; Camerer 2013). More recently, the complementarities in coordinating different activities have attracted attention. The concept of complementarity has been described as task interdependency by Simon (1976), whereas Milgrom and Roberts (1990) used a mathematical-based model to look at its role in manufacturing. The latter explained the complementarity in terms of technological, marketing and organizational activities associated with production, which impacted marginal returns. They found the changes in marketing (for example higher quality) and organization (for example low inventory and short production cycle) that accompanied the flexible manufacturing production system was not accidental, but associated with an intended business strategy to exploit the benefits of complementarities. Milgrom and Roberts (ibid.) therefore pointed out the role of a decisionmaker in addressing the issue of coordinating complementary activities for profit maximization. 
Departing from the micro-level approach, early sociologists focused on the integration of different parts of firms that enable them to pursue activities, enabling the fulfilment of collective goals and objectives (Weber 1947; March and Simon 1958; Parsons 1960). Recent management theorists critically defined coordination as 'the process through which people arrange actions in ways that they believe will enable them to accomplish their goals' (Quinn and Dutton 2005). This suggests that coordination may not necessarily lead to optimum outcome, and may result in the completion of arranging certain activities and goal achievement or the completion of activities with unsuccessful outcome. Such differences in the required coordination and actual coordination for tasks was described as coordination gaps and could negatively impact performance (Gerwin 2004).

We will focus on the positive aspect of coordination among successful projects when discussing the production and distribution of new products in digital media. Projects are the central unit of firm organization within digital media production, and are characterized by the diversity of skills among the project members and the temporal limitation of their collaboration, as discussed by Goodman and Goodman (1976), Jones (1996) and Grabher (2002). For instance, a project team of creative and technical professionals will work with support workers to produce a TV programme, which will then be distributed by a broadcaster to the viewers. This project team will include members of the TV production firms, artistic and technical professionals outside the firm; the project team will be reorganized during different stages of the production before eventually disbanding after the delivery of the completed programme to the broadcaster.

The coordination process of projects among digital media firms are associated with their budgetary practice; for example, the planning for online television is budgeted for the complete series, which will usually finish within several months; the planning of an online downloadable game is budgeted for the complete game, which could take several months or years to complete; whereas that for an online magazine per issue is published weekly, fortnightly, monthly or bi-monthly. The commercial aspects of the aforementioned creative sectors mean that all projects are subjected to budget constraint, and the bottom line is 'to cut the cloth according to the means'. Pavitt (1998, p.434) stated the importance of coordination as: 'Firms rarely fail because of an inability to master a new field of technology, but because they do not succeed in matching the firm's systems of coordination and control to the nature of the available technological opportunities.' The managerial capability to coordinate firm resources is therefore of utmost importance in creating new successful digital media products.

The project teams (as opposed to the firms) are responsible for the 
outputs in digital media. As property rights confer ownership of resources that lead to decision-making power (Casson 1982), project teams will have to harmonize their decisions in resource coordination with internal administrative units and external suppliers concurrently. For instance, a television production project will have to negotiate the time of producers and assistants involved since they would also be required on other projects across different time spans. There will be further coordination with external suppliers of inputs such as script writers, actors, camera crew, audio team, sound editor, and so on, within different fixed time schedules to enable the project to proceed smoothly.

Finally, coordination can also be distinguished into routine and nonroutine coordination. March and Simon (1958) advocated the coordination of work units using pre-specified programmes or mutual adjustment for routine coordination. The mechanism for non-routine coordination, on the other hand, includes the use of formal contracts and the use of interpersonal or institutional trust. The unique crafts-based nature of digital media products means that non-routine coordination is dominant. The key ingredient in non-routine coordination is 'the monopoly of some item of information' (Casson 1982, p.120). Casson (ibid.) further suggested that when information was synthesized, it enhanced the quality of individual decision-making. In the context of digital media production, the information could be related to the availability and the quality of creative inputs such as high-profile supporting casts which could appear in the filming process at the allocated time for the television programme production.

\section{RESOURCES AND CREATIVE INPUTS}

The coordination of digital media projects revolves around finite resources. Firm resources have been traditionally classified into tangible and intangible resources; they are important productive assets that enable firms to reduce their costs structure as well as increasing their margins or sales through differentiation during the value-adding activities (for example Wernerfelt 1984; Barney 1991; Grant and Jordan 2012). Florida (2002, p.xiii) stated that 'human creativity is the ultimate economic resource'; indeed, Grant and Jordan (2012) discussed the human resource along the tangible and intangible resources. Human resources are distinctive from tangible resources such as equipment, buildings, land and money since the latter can be easily observed and accounted for through objective assessment, and could be recorded in the firms' annual financial statements. Human resources also differ from the majority of intangible 
resources such as branding, reputation, culture and knowledge, as they are partially protected by the contract system. ${ }^{10}$ The inclusion of human resources could be traced to their durability; Grant and Jordan (2012) stated that 'although employees are free to move from one firm to another (most employment contracts require no more than a month's notice on the part of the employee) - in practice most employment contracts are long term' (p.119). Human resources embody not simply the skill or talent of individuals in a specific domain (for example script writing knowledge); they also extend to inter-firm relationships once established, tacit knowledge concerning the routines performed by those within the firms, culture and structure adopted in the firms, and so on. As Bowman and Swart (2007, p.490) stated: 'Although a firm may possess a valuable resource like a brand or special equipment, this resource was either artfully "picked", or it was created by human inputs.' The recent focus on the creative economy and the contribution of those outside the creative industries further highlighted the importance of human resources towards economic growth (DCMS 2014). ${ }^{11}$

The complexity of creative industries, such as digital media, was discussed by Caves (2000), who highlighted the unique characteristics of human resources, that is, craftsmanship mentality, diversity of skills, vertically differentiated skills and the need for temporal coordination. Caves (2000) stated that the labour 'cares vitally about the originality displayed, the technical prowess demonstrated, the resolution and harmony achieved in the creative act' (ibid., p.4); he also acknowledged complex creative products require diverse skilled labour which are not substitutable. Caves explained that 'you can produce a gadget with two units of labour and one capital, or one of labour and two of capital; perhaps four units of labour and no capital will do the job' (op. cit., p.5); however, all the inputs must present and perform at or above some threshold level of proficiency in the production of creative products. Added to the diverse skill requirement are creative human inputs - such as directors, actors, programmers, musicians, artists, writers - and they differ in terms of quality and availability; this therefore further challenges the coordination process. Caves further differentiated creative inputs from humdrum inputs. In the context of online TV, games and magazines, humdrum inputs represent the use of agencies, administrators, and so on, which are high in uniformity and can be obtained at rather uniform market prices. Consequently, the procedure to acquire them can be coordinated through the use of standard routines. Overall, creative human inputs are dynamic and non-standardized; hence, they are difficult to manage.

Tables 1.1, 1.2 and 1.3 show the resources utilized in digital media production in terms of their commercial, artistic and technical characteristics, 


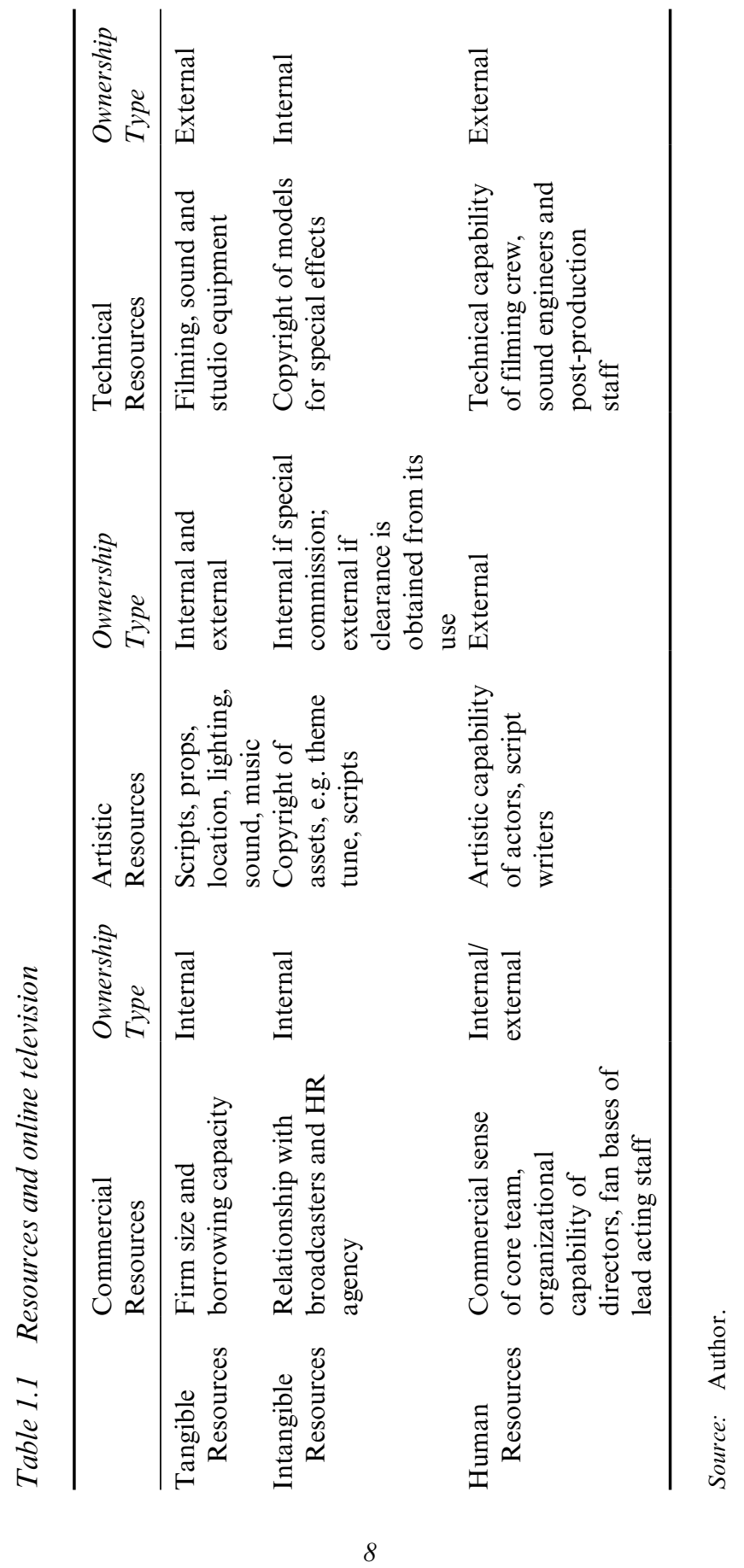




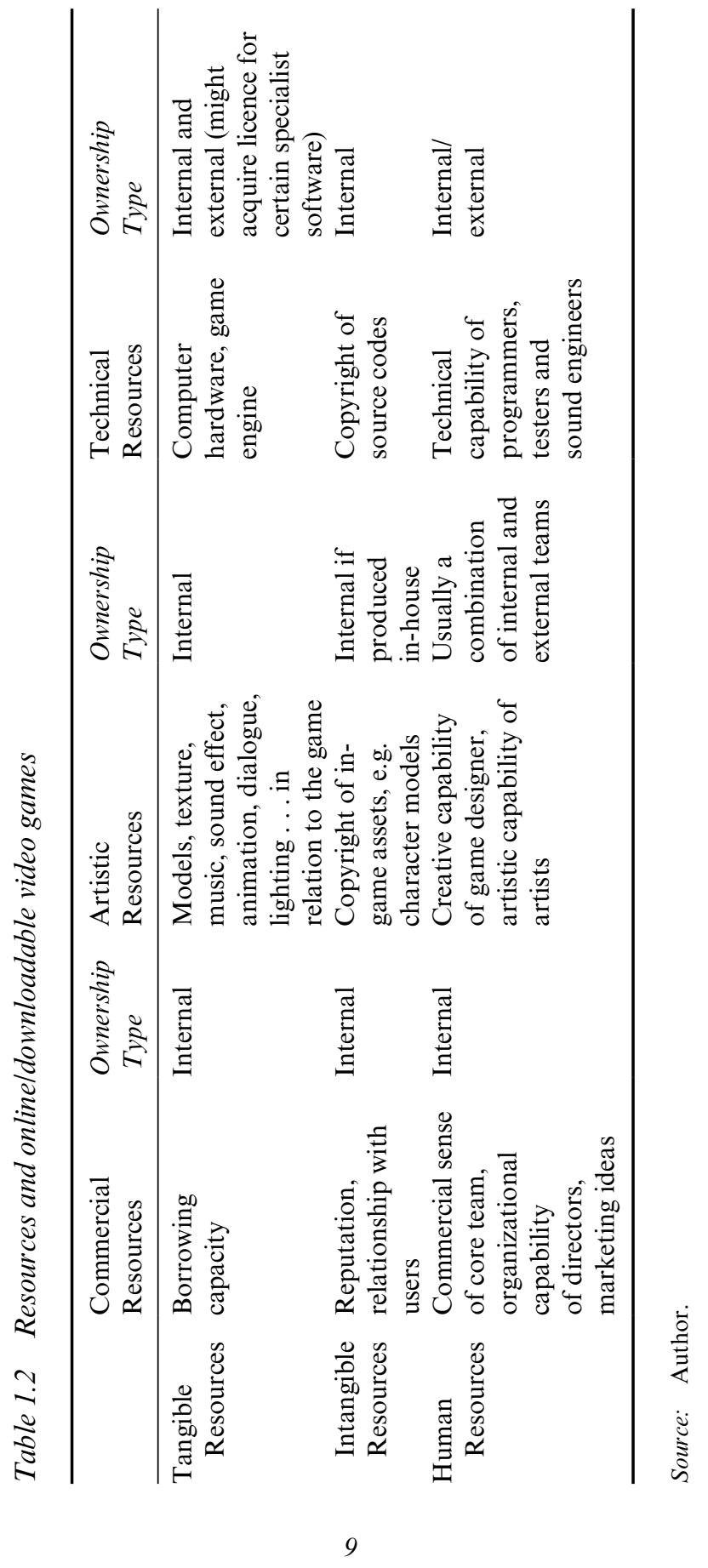




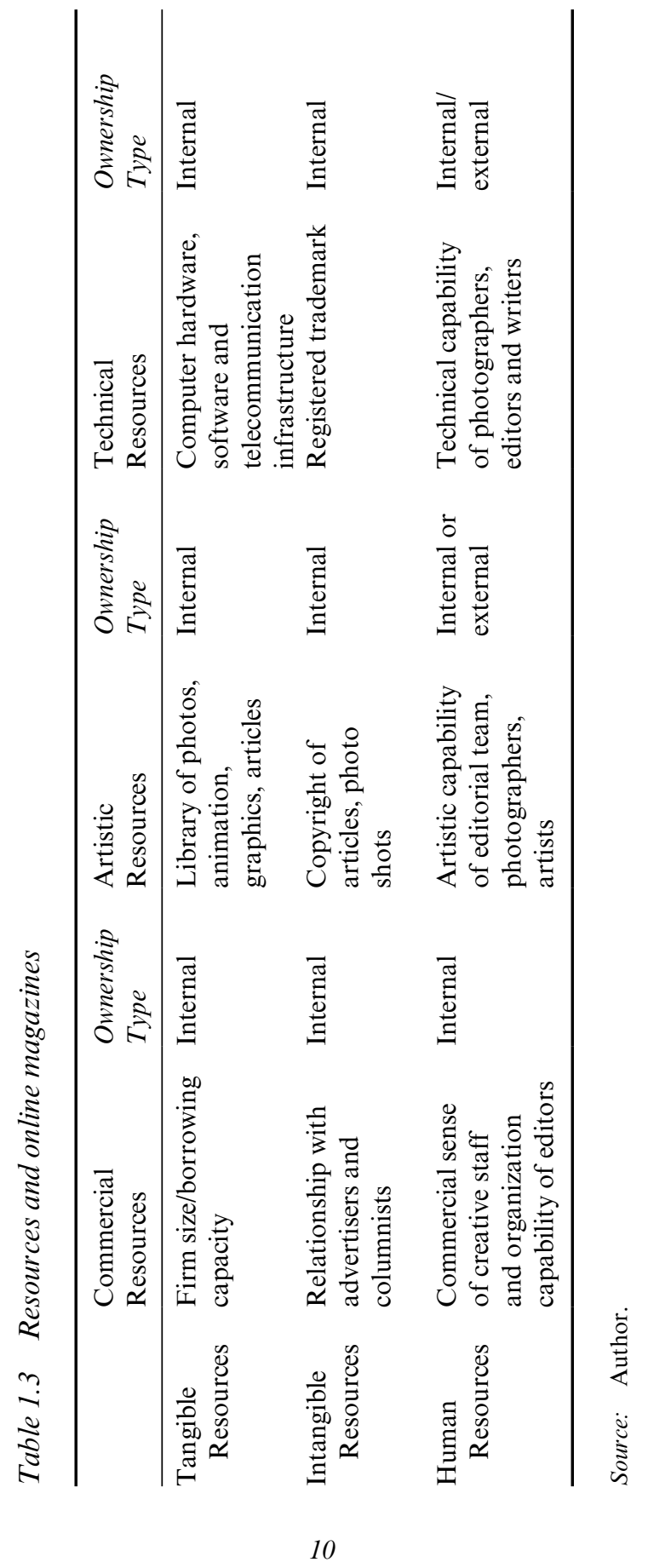


and the types of ownership that are most commonly observed. Though some of these resources, such as animators for online games, are critical in the value-creation process, they have low asset specificity 12 and therefore can be provided by external suppliers. ${ }^{13}$ Other resources, such as filming equipment and recording studio, ${ }^{14}$ could be considered as generic resources, which are relatively easy to acquire. We will revisit the concept of outsourcing creative inputs among digital media products in Chapter 5.

\section{DECONSTRUCTING ENTREPRENEURIAL CREATIVITY}

In this section, we will look at the concept of entrepreneurial creativity. We will first review the literature concerning creativity and entrepreneurship. Both creativity and entrepreneurship are complex concepts. For example, creativity has been used interchangeably with the concept of innovation. Some theorists such as Amabile et al. (1996) stated that 'all innovation begins with creative ideas' and 'the first is a necessary but not sufficient condition for the second' (p.1154); hence, innovation could be seen in terms of the implementation of the ideas in products, processes, practices, and so on, whereas creativity represents the early stage of innovation in which new ideas are conceived. However, this distinctive theoretical separation of the two concepts is not unproblematic since creativity could not be simply confined to the early stage of innovation, and could be 'a cyclical, recursive process of idea generation and implementation' (Anderson et al. 2014, p.1299). Similarly, entrepreneurship is a concept with a wide range of connotation. Casson et al. (2006, p.9) wrote that 'Entrepreneurship can be regarded as one of the components of human capital. It is a skill in processing information in connection with judgemental decisions. It includes using social networks to collect information, memorizing and recalling information effectively through association of ideas, and interpreting information using appropriate mental models.' We will revisit the development of the concepts and its linkage with this notion of human capital in the following section.

\section{Creativity ${ }^{15}$ as Novelty and Value}

Creativity can be interpreted as a general concept, such as creative personality, or a domain-specific concept, such as creative writing; it can be classified in terms of the underpinning theoretical disciplines (for example scientific creativity, artistic creativity, architectural creativity, musical creativity, engineering creativity) as well as practical applications (for 
example marketing creativity, strategic creativity, design creativity). The study of creativity by theorists can be traced to the first psychometric study of Francis Galton in relation to English scientists (1874). On the other hand, the practical application of creativity has been explored in terms of the determining factors within specific domains. For example, marketing creativity has been examined by researchers in the context of new product development and marketing programme implementation (Andrews and Smith 1996; Sethi et al. 2001; Im et al. 2012).

The definitional issue of creativity has been discussed by researchers such as Mumford and Gustafson (1988), Anderson et al. (2014) and others. Amabile (1983, 1988, 1997), who pioneered the study of organizational creativity, defined creativity as the ability to produce novel and appropriate ideas to open-ended problems in any domain of human activity. She stated that within individuals, creativity was a function of three components: intrinsic motivation ${ }^{16}$ (that is, a work style characterized by concentrated effort, an ability to set aside problems and high energy), expertise (that is, domain-specific knowledge) as well as creative thinking skills (that is, a cognitive style that involved coping with complexities and breaking one's mental set during problem-solving). In her study of the computational theories of creativity, Boden $(1990,1994)$ addressed creativity as the mental and cognitive process in conjunction with new, surprising and valuable ideas. Boden (2004) wrote that creativity involved individuals' evaluation of the ideas they generated: 'The new idea must be compared to some pre-existing mental structure, and judged to be "interesting" by the relevant criteria' (p.76). These definitions, which set a boundary for discussing creativity and highlighted the decision-making element, reflect the mainstream academic literature around the concept.

Though creativity has been a much valued concept within Western civilization, it has historically been overlooked in the Eastern worlds. Creativity was interpreted by ancient Greeks in terms of an individual's daimon; indeed, Plato and Plotin believed that poetry and art were attributed by divine inspiration. Creativity has been emphasized as a unique individual quality since the age of Enlightenment, where institutions in Venice and London began to grant patents to inventors in 1474 and 1624 respectively (Sherman and Bentley 2008). With the growing importance of creative industries in reshaping the industrial structure of advanced economies such as the US and the UK, creativity is identified as the highest level of human achievement that could enhance a firm's performance and national competitiveness. The uniqueness of individuals as embedded in creativity means that the cultural value of Anglo-American individualism has been endorsed within the creative industries. Overall, the fundamental point of creativity lies in the notion of self-actualization, 'when we are 
involved in [a creative activity], we feel that we are living more fully than during the rest of life' (Csikszentmihalyi 1996, p.2).

The study of creativity has become a contemporary phenomenon with the work of practitioners; one of the widely known practitioners is Edward De Bono, who advocated the use of the lateral thinking process in 1967. It should, however, be noted that considerable theoretical and empirical creativity research has been undertaken by US psychologists, such as Dewey (1990), Wallas (1926), Spearman (1931), Guilford (1967), Torrance (1974), Amabile (1983), Sternberg and Lubart (1991), Simonton (1999) and Mumford et al. (2013), who approached the concept with an individualist and socio-cultural perspective.

The individualist perspective viewed creativity as a new mental combination and could be traced to literature focusing on individual differences (for example intelligence, personality traits and psychodynamics) as well as cognitive processes within the human brain. In particular, the cognitive theory of associationism argues that the mind is full of ideas which are organized by means of various associations such as similarity, contrast, frequency, cause and effect, and so on, and creativity relates to combinations that grow out of ideas in our minds. Creativity is the mental processes that are employed in problem-solving (for example Wallas 1926; Rossman 1931; Scott et al. 2004; Sternberg 2006), whereas problems relate to any task that individuals attempt to accomplish. In their seminal book chapter, Newell et al. (1962, p.66) wrote: 'creativity activity appears simply to be a special class of problem-solving activity.' Their view was supported by the early practitioner A.F. Osborn in 1964, who regarded problemsolving as 'the best of all creative exercises' (p.165). Osborn suggested the following processes:

1. Orientation: Picking out and pointing out the problem.

2. Preparation: Gathering material relevant to the problem.

3. Analysis: Breaking down the relevant material.

4. Hypothesis: Piling up alternatives by way of tentative ideas.

5. Incubation: Letting up in order to invite illumination.

6. Synthesis: Putting the pieces together.

7. Verification: Judging the resultant ideas.

Osborn (1964) also mentioned that the process was far from sequential; for example, one might try to obtain more data after the incubation of ideas; however, he suggested that 'judgment should be stalled until we reach the stage of verification' (p.165). One might also add that the aforementioned process could end with externalization of ideas, which were regarded as an integral part of creativity by mainstream theorists. 
The socio-cultural perspective shifts away from the individual and examines creativity within the environment where teams and firms operate; it tends to define creativity as the generation of a product that is judged to be new and useful. The notion of creativity is therefore similar to the concept of innovation used by business researchers. Indeed, Wehner et al. (1991) depicted the use of terminology concerning creativity and innovation with the blind men and the elephant fable: 'we touch different parts of the same beast and derive distorted pictures of the whole from what we know' (p.270). The study of creativity within the social and cultural system has been referred to as a confluence perspective by Robert Sternberg (1999), who states that a convergence of multiple components is necessary to generate creativity. As Heilman (2005) wrote that knowledge on its own was inadequate to explain creativity, which required 'the brain [to] manipulate stored knowledge' consciously or unconsciously (p.17). Amabile's work (1983, 1996, 2001), as mentioned above, described creativity in terms of the convergence of expertise, motivation and creativity-relevant skills and is the most widely adopted model within this perspective. Further discussions on these streams of work on creativity will be provided in Chapters 3 and 4.

\section{Entrepreneurship and Coordination}

The term entrepreneurship was coined by the French economist J.B. Say some 200 years ago; since then, economists have been interested in the role and function of the entrepreneur. Cantillon $(1755, \mathrm{p} .47)$ conceptualized entrepreneurs as organizers of factors of production who undertook the activities of purchasing products, repackaging them and then marketing the products within an agrarian economy where prices were unpredictable. He wrote (ibid., p.47): 'The Farmer is an undertaker who promises to pay to the Landowner for his Farm or Land, a fixed sum of money ... with assurance of the profit he will derive from this enterprise.' Succeeding generations of economists have expanded the roles of entrepreneurs in terms of uncertainty-bearers, arbitrageurs, alert discoverers, coordinators, innovators and decision-makers.

Knight (1921) discussed the profits obtained by entrepreneurs as the rewards for their bearing of uncertainty. Improvising on Cantillon's idea, he made a distinction between risk and uncertainty involved in entrepreneurship. The former existed when outcomes of events were uncertain, yet these outcomes could be predicted with some degree of probability. The latter, however, related to events when the probability of outcomes could not be calculated. Knight therefore viewed entrepreneurs as calculated risk-takers, their skills lying in their ability to handle the 
uncertainty associated with changes. While Knight regarded entrepreneurs as resource-owners, Schumpeter (1911) addressed the innovative capacity within entrepreneurship. The innovative roles of entrepreneurs, in Schumpeter's view, were the driving force in economic development. Schumpeter ascribed discriminating motivations to entrepreneurs in terms of 'building dynasties', 'the will to conquer', 'the exercise of ingenuity' and of 'overweening self-confidence'. Schumpeter proposed that innovation could lead to new products, new methods of production, new markets, new sources of supply of material inputs and new types of organization.

More recent economists such as Kirzner $(1973,1979)$ theorized that entrepreneurs were individuals both alert to profitable exchange opportunities and the ability to exploit them; for example, he illustrated alertness with the case of arbitrageur, that is, "the person who discovers the opportunity to buy at low prices and sell the same items at high prices, because of differences in intertemporal or interspatial demands'. He further noted that entrepreneurs could identify suppliers and customers and perform market intermediary activities. The entrepreneurs used their unique information advantages to take advantage of profitable opportunities and generate profits. He wrote (1992, p.7), 'recognizing the propensity of the entrepreneur alertly to discover failures in existing patterns of co-ordination among market decisions, permits us to see how systemic (equilibrating) market tendencies can be traced back to creative, originative, entrepreneurial alertness'.

Casson (1982, p.13), who incorporated the historical themes of risk, uncertainty, innovation, perception and change, provided a synergy of entrepreneurship and described it in terms of coordination; entrepreneurs are individuals who specialize in 'taking judgemental decisions about the coordination of scarce resources'. Accordingly, entrepreneurship represents a comparative advantage in making decisions or a capacity for successful problem-solving and reconciling scarce resources within the uncertain environment. Casson (ibid., p.24) stated that judgemental decisions occurred when 'different individuals, sharing the same objectives and acting under similar circumstances, would make different decisions'. He explained that the different decisions were results of different access to information or different interpretations of the same information. Entrepreneurs synthesize existing information during the process of opportunity recognition in relation to the founding of new firms as well as the operation of successful firms. For example, when launching new products, they needed to synthesize information in relation to buyers' preferences with information concerning the costs of the new design; they also needed to synthesize information concerning production method and the availability of inputs when assessing the economic feasibility of new 
production technique. Casson added that 'the entrepreneur does not necessarily possess any single item of information that no one else does. His advantage lies in the fact that some items of information are complementary, and that his combination of complementary items of information is different from everyone else's' (op. cit., p.147).

Shane (2003) further explained the role of creativity and judgemental decision-making. He wrote that judgemental decision-making was nonoptimizing and therefore could not be programmed as a mechanistic process, hence requiring creativity (p.40). He highlighted that the entrepreneur would have to act creatively 'to form opinions about assumptions that are as yet unproven' (ibid.). This view was similar to Shackle (1979), who suggested that the entrepreneur who made the choice on scarce resources would need to be imaginative as 'he can find in himself and his surroundings only so much of the gifts of intellect and concentration, of moral effort and resolution, of physique, and of the power to out-reach by imagination his pressing weariness and despondency; can find in his possession only such-and-such of the tools and systems, the sources of chemical or biological energy, the materials, and the power of persuasion to elicit the aid of others'.

\section{ENTREPRENEURIAL CREATIVITY AND THE VIRTUAL WORLD}

Entrepreneurial creativity has been defined as new thinking that shaped entrepreneurial behaviour in existing or new firms. Ko and Butler (2007) found that entrepreneurial creativity was linked to the development of new products among high-tech entrepreneurs; they proposed a framework for entrepreneurial creativity consisting of a solid knowledge base, a well-developed social network and alertness to opportunities that enhance managerial ability to 'connecting the dots'. In a similar vein, Amabile (1997, p.20) stated that entrepreneurial creativity is 'the generation and implementation of novel, appropriate ideas to establish a new venture (a new business or new program to deliver products or services)'; her notion of novel and useful ideas could be related to the products or services themselves, finding a market for the products or the services, methods to produce and deliver the products or services, as well as ways to secure resources to produce and deliver the products or relevant services.

In order to combine the three key concepts - judgement, coordination and creativity - we will adopt a definition that builds on Amabile's confluence perspective of creativity as well as tracing back to Cassonian entrepreneurship. Though judgement and creativity might seem to be a 
dichotomy or opposed concepts, there was a long tradition to reconcile their co-existence. For example, Schumpeter (1934, p.85) stated that 'the success of everything depends on intuition, the capacity of seeing things in a way which afterwards proves to be true, even though it cannot be established at the moment, and of grasping the essential fact, discarding the unessential, even though one can give no account of the principles by what this is done'. Osborn (1953, p.39) wrote that 'judgment can help keep imagination on the track, and imagination can help enlighten judgment'. Hence, entrepreneurial creativity is defined as individuals specializing in making judgemental decisions to coordinate scarce commercial, artistic and technical resources with novelty and usefulness in order to produce new digital media products. The distinction of resources into commercial, artistic and technical resources mirrors the project organization among digital media firms. For example, Movitz and Sandberg's (2009) study of Swedish digital media firms showed that their value-adding activities were clustered across three areas: economy (for example develop ways to commercially exploit technological potentials), aesthetics (for example sound/music production) and technology (for example programming). Such a deployment pattern of resources therefore supported the classification in terms of commercial, artistic and technical resources. For instance, an online TV programme involves harmonizing decisions concerning the division of work among the production team and the broadcaster (who adopt the commercial perspective), actors and writers (who represent artistic resource) as well as filming crew and sound technicians (who are technical in nature).

As the organizational process within online game, TV and magazine production/distribution is dynamic and fast changing, and routines are likely to diverge from existing patterns, the three sectors provide an excellent background to explore entrepreneurial creativity among micro-, small- and medium-sized firms as well as global firms. The diverse nature of commercial, artistic and technical resources has implications on coordination among project teams. Carton and Cummings (2012) discussed the functional division within teams could be on the basis of diverse identity; they explained that individuals shared the same sense of distinctiveness, shaping the sense of belongingness that simplifies the social world structure. In other words, actors and actresses tended to have network connections, shared values and interacted on an informal basis, whilst not overlapping with those of the film crew or sound engineers. This suggests that one of the challenges in the coordination of different activities will be negotiating different identities and values held by different sub-teams.

Business strategists have argued that it was not the amount of resources owned by the firms but how they deploy the available resources that 
generates sustainable competitive advantages (for example Prahalad and Hamel 1990; Grant 1991). Writers such as Teece (1986) and Christensen $(1995,1996)$ suggested that the coordination of complementary resources was critical in technology-intensive new-to-the-world products. As online games, online TV and online magazines require the alignment of commercial, artistic and technical resources internally and externally along the value chains, good judgemental decision-making in their coordination plays a key role in successful products. Casson (1982, p.29) stated that decision-making was a three-stage process: formulation of the decision problem, generating the data and execution of the decision. He also pointed out that good judgement in decision-making requires individual qualities, as shown in Table 1.4.

Table 1.4 shows that certain individual qualities enhance judgemental decision-making; in particular, the imagination required for specifying options during the formulation of the decision problem and the foresight used in estimating incomplete data during data generation are extremely valuable, since they are 'essential for successful decision-making', 'scarce' and 'difficult to screen for' (Casson 1982, pp.34-5). ${ }^{17}$ Recent work by Osburn and Mumford (2006) and Mumford et al. (2013) reiterated the importance of imagination and foresight. Mumford et al. (ibid., p.252) highlighted five points in relation to creative problem-solving: (1) processing activities mediate the relationship of abilities and expertise on creative problem-solving; (2) each process makes a unique contribution to the prediction of performance on creative problem-solving tasks; (3) problem construction, conceptual combination and idea generation seem to be especially noteworthy as predictors of problem-solving performance; (4) these processes predict creative problem-solving performance across many domains; and (5) effective execution of these processes is strongly associated with the production of high-quality, original and elegant solutions. Overall, the intangibility of the human resources involved reflects the inherent difficulty for digital media firms to coordinate creative products. Chapter 3 will continue this theme, investigating how ideas for new contents are generated among Scottish game firms.

\section{METHODOLOGY}

The three digital media sectors on which we focus in this book are invaluable as they involve creativity and coordination, where judgemental decisions are important. Though these sectors drive the growth of creative industries within advanced economies, it is under-studied and the subject deserves more attention. This book was based on longitudinal research; 


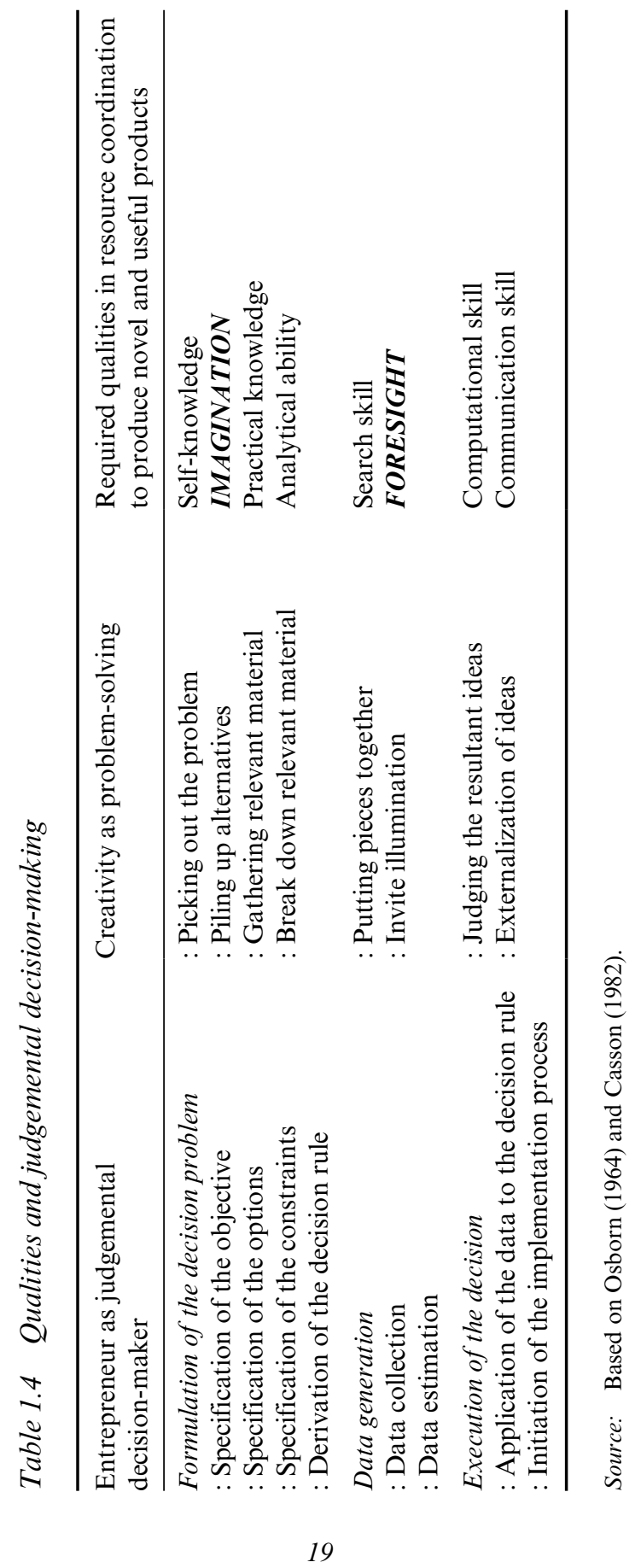


in particular, 12 firms are discussed in depth in the following chapters to illustrate the concepts of entrepreneurial creativity. Firms are a coalition of entrepreneurs; the complex coordination required during value-creation within these digital media firms therefore provides an excellent setting to examine judgemental decision-making and the subsequent coordination on creative production. In this book the qualitative analysis of entrepreneurial creativity is based on comparative analysis and the data collected is compared with concepts and theories developed.

A retrospective approach will be taken to study the process of entrepreneurial creativity. In Chapter 2, London-based digital media firms LDN1 (an online TV programme producer), LDN2 (an online downloadable game producer) and LDN3 (an online magazine publisher) were chosen to provide an overview of conceptualizing new ideas, organizing creativity and managing end-user relationships. The three firms owned considerable intellectual assets and shared the characteristics of being positioned in niche market segments, and attracted users being referred to as ideas people, core users and cult followers. Access to key decision-makers involved in the projects were through personal introduction and personal invitation, which was essential to data collection; furthermore, primary and secondary data were collected across the three firms, which included marketing material, company reports, industry websites, news reports and blogs.

Chapters 3-6 elaborate on the processes of entrepreneurial creativity discussed in Chapter 2. The data in Chapter 3 concerning the conception of new ideas among case study firms SCT1, SCT2 and SCT3 were collected during in-depth, face-to-face interviews with their lead founders. The firm interviews (which lasted between one and two hours) were recorded and were transcribed by the author's assistant, who is also a video game enthusiast. Supplementary data were collected through the firms' websites and industry publications such as Develop, Edge and MCI. Chapter 4 discusses the conception of new ideas within the entrepreneurial creativity process from the perspective of firms, which include Climax Studios, Creative Assembly, Exient Entertainment and Rockstar North. Primary data were collected through firm publications and 12 personal interviews with stakeholders such as employees, parent firms and ex-employees, while secondary data were based on public domain information. Complementary industry interviews were also used to enrich our understanding of entrepreneurial creativity. As the description of culture, structure and network was collected from multiple data sources, a more accurate picture was developed than with the case studies utilizing only firm-level information. The triangulation of the data collected also enhanced the validity and reliability of findings. 
Chapter 5 utilizes multiple sources of information derived from micro-, small- and medium-sized firms as well as global firms to examine the second process of entrepreneurial creativity, that is, the organization of creativity. Furthermore, information was obtained from firms specializing in outsourced services. Longitudinal industry data were collected from industry publications, industry reports and forums, while firm-level data were collected in the UK via in-depth interviews. The starting point for the face-to-face interviews was an overview of growth and the informants' roles in the firm. Questions asked during the interviews focused on the what, who, where, why, when and how of outsourcing, and a probe-learniterate approach was adopted. The information, though mainly related to a specific timeframe, was enriched and cross-checked with industry data to search for patterns over time.

Chapter 6 looks at the final process of entrepreneurial creativity and examines viral marketing within the online games RuneScape and Angry Birds. One of the high-profile players of Angry Birds was reported to be British Prime Minister David Cameron (BBC 2012). Primary data used in this chapter was obtained from personal interviews with seven players (aged between 15 and 45), firm websites and relevant social media sites, whereas secondary data included industry interviews and reports. Finally, Chapter 7 summarizes the findings and discusses the theoretical and practical contribution of the book.

\section{CONCLUSION}

This chapter has utilized the theoretical underpinning of entrepreneurship and creativity to define entrepreneurial creativity as individuals specializing in making judgemental decisions to coordinate scarce commercial, artistic and technical resources with novelty and usefulness in order to produce new-to-the-world digital media products. Schumpeter (1934) argued that firms had to constantly adapt to a changing environment due to creative destruction; change is indeed a powerful driving force within the digital media industry where firm organizations are formed project by project. The project teams that encompass internal and external talents represent a temporary coalition with shared objectives in creative production, and the role of project managers is to orchestrate the creative commitments. As Stoneman (2010) pointed out, we are now at the interesting time when changes in product functionality have been outpaced by changes impacting sensory and intellectual perception as well as the aesthetic appeal of products. This means the understanding of the coordination of scarce resources and the continuous realignment 
of resources with the evolving environment is critical. In the following chapter, we will elaborate on three sub-processes of entrepreneurial creativity: conception of new ideas, organization of creativity and managing the end-user relationship to highlight the role of judgemental decisions using case studies of online games, online television and online magazines. Then Chapters 3-6 will investigate key issues within these sub-processes before our conclusion in Chapter 7.

\section{NOTES}

1. This is as opposed to new-to-the-firm products and represents creativity at the firm level.

2. We differentiated digital media products such as online games from digital media services such as advertising and e-commerce.

3. The terms online television, online game and online magazine will be used when we refer to these digital media products.

4. Concept-intensive products refer to products with high labour skill intensity, low minimum efficient scale, low initial capital investment, short product lifecycle and high transportability. For example, though the overall concept of the BBC's Strictly Come Dancing showing celebrities and their professional dance partners competing in a variety of dances and then judged by a combination of public voting and panels is not complicated, there are further creative inputs from the professional dancers to use concepts and portray them in choreography.

5. Silent Hill was released in 2006, while Silent Hill Revelation was released in 2012.

6. The online version of Families, that is, Familiesonline.co.uk, was launched in 2000 and targeted families within the A, B and C1 categories. Though the printed version of the magazine is freely distributed across the UK, it generates substantial revenues through advertising from nationally and regionally based firms.

7. The printed magazine of The Economist's spin-off Intelligent Life was first published in 2007; it represented a departure from the political and economic news content of The Economist.

8. The DCMS $(1998,2001)$ defined creative industries as 'those industries which have their origin in individual creativity, skill and talent and which have a potential for wealth and job creation through the generation and exploitation of intellectual property'. This definition has been acknowledged by the CBI (2014) as well as the OAS, IDB and British Council (2014).

9. As some writers, such as Bronson and Merryman (2010), pointed out, America now faced a creativity crisis; our focus on the UK was timely. As Taylor (2014) stated, 'Britain is creative, officially. In 2010 Britain had 106,700 creative enterprises, which contributed $£ 59$ billion to the national economy' (p.590).

10. Intangible intellectual properties such as computer codes, patents and trademarks, on the other hand, are fully protected by the legal system.

11. The DCMS (2014, p.8) distinguished the creative industries from the creative economy. The former includes 'creative jobs in the creative industries' and 'jobs in the creative industries classified not as creative'. The definition of creative economy goes further and also includes 'creative jobs outside the creative industries'.

12. Within the behaviour assumption of bounded rationality and opportunism, Williamson (1985) showed that asset specificity was a major cause of transaction cost. Asset specificity refers to assets that are dedicated to the production, such as dedicated machinery, and cannot be easily redeployed for other purposes. High asset specificity, as a consequence, generates high transaction cost. 
13. Casson (1987) suggested that the information asymmetry regarding the quality of inputs could be a reason for firms not using outsourcing. However, since there is a cluster of world-class suppliers of creative inputs in the UK, quality control is less of an issue.

14. The filming studios in London, however, are in short supply. Studios as a generic resource are limited to those outside the capital of the UK.

15. Cropley et al. (2013) stated the 4Ps of creativity are: person, process, product and press (or the social context).

16. Intrinsic motivation relates to performing certain activities for their own sake, such as enjoyment, which is opposed to extrinsic motivation, such as performing the activities because of external rewards such as a bonus.

17. Casson (1982, p.34) explained the concept of scarcity in terms of the skewness in the distribution of personal qualities: 'A scarcity of personal qualities usually occurs, not because everyone has only a little of the quality, but because only a few people have the quality and many people do not have it at all.' 